\title{
From the Editors' Desk: What You Don’t Know Could Hurt You
}

\author{
Mitchell D. Feldman, MD, MPhil \\ Division of General Internal Medicine, University of California, San Francisco, San Francisco, CA, USA.
}

$J$ Gen Intern Med 25(11):1139

DOI: $10.1007 / \mathrm{s} 11606-010-1505-8$

(c) The Author(s) 2010. This article is published with open access at Springerlink.com

A n e-mail that would have usually been categorized as "junk" somehow managed to elude the university spam filter and made its way into my in-box; the subject line read: "What Doctors Need to Know About Facebook." The e-mail was inviting me to participate in a webinar that promised the participants that, among other wonders, they would learn to use Facebook as a "valuable tool for sharing information with colleagues." Really? As a late and somewhat reluctant adopter of Facebook, I have been unconvinced of its value for me personally or professionally, and have mainly ignored the many "friend" requests that somehow began showing up in my e-mail after I finally signed up a few months ago; some came from patients and their families, some from people whose names I barely recognized (none, alas, from long lost flames).

I was surprised, however, when a former colleague found me through my new Facebook presence and said she was thrilled to see the wonderful pictures of my kids. I was surprised because I had not posted any pictures of my now grown children; surprise gave way to dismay when I realized that the photos she had accessed were actually on my 19- and 23-yearold children's Facebook pages, many of which were not suitable for sharing at a family reunion, and certainly not what I would choose to share with colleagues or patients.

The potential, and potential perils, of Facebook and other Internet and social media are the subject of several papers in this month's JGIM. In one of the first empirical studies to examine the question of the availability and nature of physician information accessible on the Internet, Mostaghimi et al. searched the Internet to see what kind of professional and personal information was freely available to the average patient about a randomly selected sample of 250 internal medicine physicians in Massachusetts. They found, not surprisingly, that almost all the physicians (94\%) had either personal or professional information that could be easily accessed with a

Published online September 14, 2010 simple Google search. Perhaps more surprising was that while most of the information available was of a professional nature (such as quality rating sites, publications and in three cases, disciplinary actions), almost $1 / 3$ of the physicians had personal information available on-line on more than 200 web sites, including Facebook pages, political and charitable donations, and family and personal financial information. It is likely that most of these physicians were unaware of the extent of their personal information available on-line and would not have chosen to share much of it if given the choice. As Mostaghimi et al. state: "Most physicians limit their self-expression during patient encounters: few physicians would wear a political pin, discuss their ongoing litigations with their neighbor, or detail charitable contributions during a patient encounter. Our study demonstrates, however, that this type of information could easily be found with a single limited Internet search."

Physicians may not only put themselves at risk when they fail to monitor their on-line presence, but they also risk compromising the integrity of the profession. The impact of the rise of social media such as Facebook on medical professionalism is the subject of an incisive Perspective in this issue by Greysen et al. They argue that the time has come for the establishment of consensus-based standards for "online professionalism." Too often, they argue, and as Mostaghami et al. found, physicians do not consider the potential impact of their on-line content and may inadvertently violate professional standards in cyberspace that they would never violate in real-time social interactions. Greysen et al. make the point that what we don't know may not only hurt us, but may also hurt others such as our patients and colleagues, and the medical profession as a whole.

Open Access: This article is distributed under the terms of the Creative Commons Attribution Noncommercial License which permits any noncommercial use, distribution, and reproduction in any medium, provided the original author(s) and source are credited.

Corresponding Author: Mitchell D. Feldman, MD, MPhil, Division of General Internal Medicine, University of California, San Francisco, 400 Parnassus Avenue, San Francisco, CA 94143-0320, USA (e-mail: mfeldman@medicine.ucsf.edu). 